\title{
De Commissie Visser, hoe verder?
}

\author{
M.A.M. Wolters ${ }^{*}$
}

\section{Inleiding}

Op 16 mei 2006 werd het parlementair onderzoek naar de TBS beëindigd. Op die datum werd het eindrapport van de Tweede Kamercommissie aangeboden aan de voorzitter van de Tweede Kamer. ${ }^{1}$ De Commissie stond onder voorzitterschap van VVD-kamerlid Arno Visser. Zelf werd ik door de Commissie als deskundige gehoord. In het hiernavolgende zal ik ingaan op de ontwikkelingen in de TBS nadat de Commissie Visser haar bevindingen presenteerde aan de voorzitter van de Tweede Kamer. In het bijzonder zal ik de ontwikkelingen rondom de TBS met voorwaarden en rondom de positie van vreemdelingen in de TBS van commentaar voorzien.

Het doel van de Commissie Visser was een effectiever gebruik te bewerkstelligen van de TBS met voorwaarden en de voorwaardelijke beëindiging van de dwangverpleging alsmede een vermindering van de druk bij de TBS met dwangverpleging. In de tijd dat de Commissie haar werkzaamheden begon werd er per jaar circa 50 keer een TBS met voorwaarden opgelegd tegenover circa 200 keer een TBS met dwangverpleging. De uitstroom uit de TBS-klinieken werd geschat op circa 80 personen per jaar. Het capaciteitsprobleem nam dan ook steeds grotere vormen aan. Dit gegeven onderstreept nog eens dat een parlementair onderzoek geen overbodige luxe was.

Marcel Wolters is officier van justitie, parket Groningen

1 Tbs, vandaag over gisteren en morgen, Eindrapport van de tijdelijke parlementaire commissie TBS, Handelingen II, 2005-2006, 30250, nr. 5. 


\section{De verbetermaatregelen t.a.v. de TBS met voorwaarden}

In het 'Plan van aanpak' van 10 oktober $2006^{2}$ is aangekondigd dat de TBS met voorwaarden zodanig zal worden aangepast dat hiervan een effectiever gebruik kan worden gemaakt. Hiermee wordt uitvoering gegeven aan een van de aanbevelingen van de Commissie Visser, om de druk op de capaciteit van de TBS met dwangverpleging te verminderen. De verbetermaatregelen staan beschreven in een beleidsnotitie. De Commissie Visser heeft drie aanbevelingen gedaan om de functie van de TBS met voorwaarden te verbeteren. Dit zijn:

1a. Verlenging van de duur van de TBS met voorwaarden van 4 naar ten hoogste 9 jaar, zodat het mogelijk wordt langer toezicht te houden.

1b. Verhoging van de maximumtermijn voor een gevangenisstraf die verbonden is aan de TBS met voorwaarden van 3 naar ten hoogste 5 jaar, zodat hij ook bij relatief zwaardere delicten kan worden opgelegd.

2. De eis van de officier vergezeld te laten gaan van zowel een advies van de reclassering als van de GGZ over de uitvoerbaarheid van de voorwaarden. Dit kan volgens de Commissie Visser gebaseerd zijn op een intakegesprek of een proefbehandeling.

3. Een acceptatieplicht bij alle klinieken zodra de strafrechter een TBS met voorwaarden, gecombineerd met een klinisch traject, oplegt.

Deze aanbevelingen worden meegenomen in het verbetertraject TBS met voorwaarden dat onderdeel uitmaakt van het Plan van aanpak. In dit traject worden bovendien nog enkele aanpassingen meegenomen die de uitvoering (naar verwachting) zullen verbeteren. Dit zijn:

4. Het verbeteren van de aansluiting tussen de tenuitvoerlegging van de gevangenisstraf en de TBS met voorwaarden.

5. Regelen van de mogelijkheid inbewaringstelling en/of opname in een forensisch psychiatrische instelling als time-out bij niet naleven voorwaarden.

6. Consequente reactie bij niet naleving van de voorwaarden c.q. aanpassing van de OM-aanwijzing TBS met voorwaarden.

2 Volledige titel: Plan van aanpak Terbeschikkingstelling en Forensische zorg in strafrechtelijk kader, Handelingen II, 2006-2007, 29452, nr. 48. 
7. Het intensiveren van het toezicht door de reclassering ('forensischpsychiatrisch toezicht').

Ad 1. Verlenging duur gevangenisstraf en TBS met voorwaarden

De TBS met voorwaarden wordt in combinatie met een gevangenisstraf opgelegd aan verdachten bij wie het herhalingsgevaar beperkt wordt geacht. In de regel wordt de TBS met voorwaarden niet voor ernstige delicten, zoals verkrachting of moord opgelegd. Het aantal jaren gevangenisstraf dat mogelijk is, wordt dan te laag geacht. De rechter heeft bij dit soort ernstige delicten de keus tussen een TBS met dwangverpleging of een lange gevangenisstraf. Door de duur van de gevangenisstraf die bij de TBS met voorwaarden wordt opgelegd te maximeren op 5 jaar, wordt het mogelijk de TBS met voorwaarden ook bij zwaardere delicten op te leggen.

Een andere manier om de TBS met voorwaarden beter te benutten is het verlengen van de duur van de TBS met voorwaarden, zodat het mogelijk wordt langer toezicht te houden. Door verlenging is langer toezicht mogelijk gedurende welke het vangnet van de omzetting naar een TBS met dwangverpleging blijft bestaan. Hierdoor lijkt de veronderstelling gerechtvaardigd dat bij het $\mathrm{OM}$ en de zittende magistratuur een grotere bereidheid zal bestaan tot het vorderen c.q. opleggen van de TBS met voorwaarden. De verlenging naar 9 jaar (en niet bijvoorbeeld 6 of 15 jaar) wordt overigens gestaafd door recidiveonderzoek. Uit recente recidivecijfers ${ }^{3}$ blijkt dat na verloop van een periode van negen jaren, de recidivekans in verhouding tot de daaraan voorafgaande periode aanzienlijk afneemt. Bij de behandeling van het rapport van de Commissie Visser hebben enkele kamerleden verzocht om levenslang toezicht mogelijk te maken. De minister heeft daarbij aangegeven dat het mogelijk moet zijn om op sommige (gevaarlijke) TBS-gestelden levenslang toezicht te houden, maar dat deze mogelijkheid niet op een justitiële titel gebaseerd hoeft te zijn. Het toezicht moet (wat de minister betreft) in dergelijke gevallen op grond van de BOPZ worden voortgezet. Hiertoe dienen de Beginselenwet TBS en de Wet BOPZ beter op elkaar te worden afgestemd. Dit wordt meegenomen bij de evaluatie van de Wet BOPZ en het wetgevingstraject. In mijn contacten met de Commissie Visser heb ik aangegeven voorstander te zijn van het de mogelijkheid de TBS met voorwaarden levenslang te laten voortduren. Ik had hierbij het oog op een (weliswaar kleine) groep TBS-gestelden die (naar verwachting) hun leven lang van medica-

3 'Buiten behandeling', WODC-recidivestudies 2005, nr. 230. 
tie afhankelijk zullen zijn. Denk in dit verband aan psychotische patiënten die bij inname van hun antipsychotische medicatie goed kunnen functioneren. Zodra ze hun medicatie laten staan, kan er recidivegevaar ontstaan en moet m.i. ingrijpen altijd mogelijk zijn. Volgens mij zijn, in die situatie, de mogelijkheden van de BOPZ wetgeving ontoereikend.

\section{Ad 2. Advies van de GGZ over de uitvoerbaarheid van de voorwaarden}

De TBS met voorwaarden kan alleen worden opgelegd indien degene die daarvoor in aanmerking komt zich bereid verklaart de voorwaarden na te leven. Deze bereidheidsverklaring is een zwakke schakel bij de oplegging van de TBS met voorwaarden. Immers, de bereidheidsverklaring biedt geen garantie dat de TBS-gestelde zich daadwerkelijk aan de voorwaarden zal houden. Hij kan een bereidheidsverklaring geven bijvoorbeeld om de oplegging van een zwaardere TBS met dwangverpleging te voorkomen. Om over motivatie en behandelbaarheid meer zekerheid te krijgen heeft de Commissie Visser voorgesteld om de GGZ, naast het advies van de reclassering, een advies aan de rechter te laten uitbrengen over de uitvoerbaarheid van de voorwaarden, waar deze voorwaarden een behandeling betreffen. Dit advies kan volgens de Commissie gebaseerd zijn op een intakegesprek en/of een proefbehandeling.

Door de RSJ en de reclassering is bezwaar gemaakt tegen de uitvoering van deze aanbeveling. De RSJ heeft in haar advies van 13 oktober 2006 over het Plan van aanpak erop gewezen dat een intakegesprek praktisch niet haalbaar is vanwege de aanzienlijke capaciteitsproblemen bij forensisch psychiatrische (poli-)klinieken en de wettelijke termijnen waarbinnen strafzaken van voorlopig gehechten dienen te worden behandeld. Ook een proefbehandeling in het kader van een schorsing van de voorlopige hechtenis acht de Raad niet haalbaar. Het recidiverisico is meestal te groot om een schorsing te rechtvaardigen. Bovendien biedt de beslissing tot schorsing met voorwaarden op zichzelf onvoldoende juridische titel om het ondergaan van een proefbehandeling af te dwingen, aldus de Raad. De reclassering vindt de aanbeveling van de Commissie Visser om de GGZ een zelfstandig advies te laten uitbrengen verwarrend en te vrijblijvend. ${ }^{4}$ De reclassering waarschuwt voor de mogelijkheid dat de GGZ en de reclassering ter rechtszitting inhoudelijk uiteenlopende adviezen uitbrengen over de invulling en haalbaarheid van de

49 juni 2006, 06/5426791. 
voorwaarden, hetgeen het rechtsproces niet ten goede komt. Liever ziet zij dat de GGZ een voorstel formuleert tot 'bereidverklaring tot opname'.

Er kan nog een bezwaar worden aangevoerd tegen het betrekken van een zelfstandig advies door de GGZ. Dit argument heeft te maken met het tijdverloop tussen het rechterlijk vonnis en de tenuitvoerlegging van de TBS met voorwaarden, indien sprake is van een gecombineerd vonnis. In dat geval moet eerst de gevangenisstraf worden ondergaan. Er verstrijkt dus een lange tijd tussen de bereidheidsverklaring en de aanvang van de voorwaarden. Hoe langer die gevangenisstraf duurt (na de wetswijziging maximaal 5 jaar), hoe minder gewicht aan de eerdere inschatting van motivatie en behandelbaarheid kan worden toegekend.

Het is overigens niet zo dat er bij de vordering door het $\mathrm{OM}$ in het geheel geen zicht bestaat op de behandelbaarheid en de waarde die gehecht kan worden aan de bereidheidsverklaring. In de pro justitia-rapportage, die door twee gedragkundigen wordt opgesteld, wordt de rechter hierover reeds nader geadviseerd. Ook de reclassering houdt hiermee rekening bij de bepaling van de invulling van de voorwaarden en adviseert hierover de rechter in de maatregelrapportage. Indien de voorwaarden een behandeling inhouden, geeft de reclassering in de maatregelrapportage aan in welke behandelinstelling en met ingang van wanneer de behandeling kan plaatsvinden. Tijdens het vorderingstraject wordt hiermee dus al rekening gehouden. In de OMaanwijzing 'TBS met voorwaarden' is aangegeven dat een TBS met voorwaarden niet mag worden gevorderd indien er geen maatregelrapportage van de reclassering voorhanden is, noch wanneer de reclassering aangeeft het toezicht niet te kunnen uitoefenen. In mijn visie zou de verplichting van een GGZ-advies over de uitvoerbaarheid van de voorwaarden een slecht idee zijn. Ik deel de opvattingen van de RSJ en de reclassering in deze. Het zal bovendien leiden tot extra aanhoudingen van strafzaken. Daar zit niemand op te wachten.

\section{Ad 3. Acceptatieplicht GGZ}

De reclassering en het OM zijn bij de tenuitvoerlegging van een TBS met voorwaarden niet alleen afhankelijk van de opstelling van de veroordeelde maar ook van de bereidheid van GGZ-instellingen om veroordeelden op te nemen. Voor bepaalde categorieën patiënten, zoals art. 37 Sr-patiënten en TBS-gestelden met dwangverpleging, geldt een opnameplicht, evenals voor personen aan wie een BOPZ-maatregel werd opgelegd. Voor TBS met 
voorwaarden geldt dit niet. Dit heeft tot gevolg dat het OM moet afzien van het vorderen van TBS met voorwaarden daar waar er geen instelling bereid werd gevonden de TBS-gestelde op te nemen. Bij de uitvoering van de motie Van de Beeten is dit probleem opgelost. In het kabinetsstandpunt naar aanleiding van deze motie ${ }^{5}$ is besloten de acceptatieplicht van de GGZ uit te breiden naar de TBS met voorwaarden. Deze acceptatieplicht moet nog wel bij wet geregeld worden. Als een rechter een klinische opname (onder welke titel dan ook) aangewezen acht, kan het niet zo zijn dat de GGZ een opname kan weigeren.

\section{Ad 4. Aansluiting gevangenisstraf en TBS met voorwaarden}

Hier speelt een lastig probleem. Nu het naar verwachting mogelijk wordt ook nog eens een langere gevangenisstraf ( 5 jaar) te combineren met een TBS met voorwaarden zal het probleem er alleen maar lastiger op worden. In het geval van een TBS met voorwaarden gecombineerd met een langere gevangenisstraf zal de reclassering enkele maanden voor de VI-datum moeten gaan regelen waar de TBS-gestelde na de VI-datum wordt geplaatst. Het is namelijk niet eenvoudig dit al voor de strafzitting te regelen. Van psychiatrische ziekenhuizen kan niet worden verwacht dat ze voor de strafzitting al kenbaar maken dat een bepaalde verdachte over (bijvoorbeeld) 2 jaar welkom is. De acceptatieplicht (punt 3) zal het probleem naar verwachting oplossen.

\section{Ad 5. Time-outvoorziening}

Tijdens de toezichtsperiode kan de TBS-gestelde een (psychische) terugval hebben. Dit kan zich uiten in het niet of onvoldoende naleven van de voorwaarden of tekenen dat er recidive kan gaan optreden. Een tijdelijke crisisopname in een behandelinstelling, ook wel 'time-out voorziening' genoemd, kan voorzien in de behoefte de TBS-gestelde te stabiliseren, zonder dat meteen moet worden gegrepen naar het zwaardere middel van het alsnog bevelen van de dwangverpleging. Hij zou niet alleen voor de TBS met voorwaarden mogelijk gemaakt moeten worden, maar ook voor de voorwaardelijk beëindigde dwangverpleging.

Het realiseren van de mogelijkheid van crisisopname bij de TBS met voorwaarden heeft naar verwachting een minderend effect op de instroom in de TBS met dwangverpleging en dus op de TBS-capaciteit. Immers, er wordt

5 Handelingen II, 2004-2005, 29452, nr. 36. 
minder snel gegrepen naar de mogelijkheid van omzetting in een TBS met dwangverpleging. Dit geldt andersom voor de capaciteit van de GGZ. Die zal in staat moeten zijn snel capaciteit beschikbaar te hebben voor crisisopname. In deze is de GGZ de aanbieder van de capaciteit, het OM en de reclassering vragers. Over de feitelijke realisatie, de functionaliteit en de capaciteit m.b.t. de time-outvoorziening zal met deze organisaties worden overlegd. Deze voorziening leidt tot vrijheidsbeperking. Daarom is hiervoor een wettelijke grondslag vereist. In de nota van wijziging bij het wetsvoorstel 'Verlenging van de totale duur van de voorwaardelijke beëindiging van de verpleging van overheidswege ${ }^{6}$ is aangegeven dat de benodigde wetswijziging zal worden gerealiseerd in het wetsvoorstel TBS met voorwaarden, dat uitvoering geeft aan de aanbevelingen van de Commissie Visser. Gedacht zou kunnen worden aan een (op vordering van het OM) door de RC te bevelen tijdelijke omzetting van de TBS met voorwaarden in een TBS met dwangverpleging met het oog op een time-out. Er zou m.i. een maximum periode van 4 weken aan kunnen worden verbonden. Binnen die 4 weken moet het OM beslissen of hij toch een omzetting in dwangverpleging wil vorderen.

\section{Ad 6. Consequente reactie bij niet naleving voorwaarden}

De effectiviteit en het vertrouwen in de TBS met voorwaarden hangen af van een goed toezicht op de naleving van de voorwaarden en een snelle en consequente reactie bij niet-naleving of dreigende ontsporing. Hoewel wettelijk goed geregeld stuit de omzettingsprocedure in de praktijk op problemen. Om deze omzettingsprocedure te verbeteren heeft het $\mathrm{OM}$ in het najaar van 2006 de OM-aanwijzing 'TBS met voorwaarden' aangescherpt. Preciezer is beschreven welke acties moeten worden verricht wanneer de voorwaarden worden geschonden of sprake is van dreigende ontsporing. De reclassering moet de officier zo spoedig mogelijk, ook buiten kantooruren, op de hoogte brengen. De officier op zijn beurt moet zo spoedig mogelijk besluiten over een mogelijk vordering tot omzetting en dit tijdig aan de reclassering berichten. De TBS-gestelde kan dan in het belang van de veiligheid snel door de politie worden aangehouden. Tot slot heeft de voorzitter van het College van Procureurs-Generaal er op aangedrongen een TBSofficier van justitie in elk arrondissement aan te stellen. Dat is inmiddels (maart 2007) in de meeste arrondissementen gerealiseerd.

6 Handelingen II, 2006-2007, 28238, nr. 6, 7 november 2006. 


\section{Ad 7. Forensisch psychiatrisch toezicht}

Het toezicht op de naleving van de voorwaarden gedurende de TBS met voorwaarden geschiedt primair door de reclassering. In het Plan van aanpak is aangekondigd dat het reclasseringstoezicht verder zal worden verbeterd in kwalitatief en in kwantitatief opzicht. Verbetering van het toezicht zal worden gerealiseerd door het ontwikkelen van een afzonderlijk product 'intensief reclasseringstoezicht' waarbij de contacturen van 30 uur worden verhoogd naar 120 uur per half jaar. Hierdoor kunnen meer controle-activiteiten plaatsvinden, kan de gespreksfrequentie met de TBS-gestelde worden verhoogd, zal vaker casuïstiekoverleg tussen reclassering en behandelende instelling kunnen plaatsvinden en zal meer contact kunnen worden onderhouden met het netwerk en ketenpartners (familie, werkgever, GGZ-kliniek, politie). Daarnaast wordt een 24-uurs bereikbaarheid bij de reclassering gerealiseerd, waardoor dreigende terugval op ieder moment van de dag kan worden gerapporteerd. De reclassering zal evenals de TBS-klinieken ook buiten kantooruren en in het weekeinde in staat moeten zijn om de toezichthoudende taak te vervullen. Ook zal de forensisch psychiatrische deskundigheid van reclasseringswerkers moeten worden vergroot, zodanig dat het risico op delictgevaar tijdens het extramurale toezicht op een verantwoorde manier kan worden ingeschat en continu kan worden gevolgd. Het lijkt me van groot belang dat de TBS-officier van justitie goed contact onderhoudt met de TBS-contactpersoon bij de reclassering.

\section{De positie van de vreemdeling in de TBS (met dwangverpleging).}

Artikel 67 van de Vreemdelingenwet geeft de IND de mogelijkheid een vreemdeling, die strafbare feiten heeft gepleegd (en daarvoor is veroordeeld) ongewenst te verklaren. Dat kan dus ook gebeuren bij vreemdelingen die werden veroordeeld tot een TBS met dwangverpleging. De tenuitvoerlegging van de TBS-maatregel levert in deze gevallen problemen op. Met TBSgestelden die niet in het bezit zijn van een legale verblijfsstatus kan geen verloftraject worden opgezet, op basis waarvan resocialisatie mogelijk is. Het is voor deze TBS-gestelden immers niet toegestaan in de Nederlandse samenleving terug te keren. Het verblijf van deze categorie patiënten in de TBS-kliniek kent daardoor volgens de minister 'een a-typisch karakter, omdat behandeling niet mogelijk is'. ${ }^{7}$ Het gebrek aan mogelijkheden tot

7 Handelingen II, 2004-2005, 29452, nr. 13, p. 1. 
resocialisatie heeft tevens tot gevolg dat de TBS van deze personen niet kan worden beëindigd, omdat niet kan worden aangetoond dat er sprake is van vermindering van het gevaar op recidive. De TBS-oplegging krijgt aldus een permanent karakter en betekent voor de betrokkene feitelijk opname op een long-stayplaats. De aanwezigheid van illegalen en ongewenstverklaarde vreemdelingen in de TBS leidt daardoor tot vergroting van de capaciteitsproblematiek. Voor het oplossen van concrete gevallen worden nu reeds de nodige inspanningen gepleegd om de betrokkene terug te laten keren naar het land van herkomst. Hiertoe bestaat slechts een beperkt aantal mogelijkheden. Een mogelijkheid is terugkeer via de Wet Overdracht Tenuitvoerlegging Strafvonnissen (WOTS). In de praktijk blijkt echter dat slechts een klein gedeelte van de TBS-gestelden zonder legale verblijfsstatus van de WOTS gebruik kan maken. De IND heeft zich inmiddels bereid verklaard om via case-management zoveel mogelijk illegale TBS-gestelden naar het land van herkomst te laten terugkeren. Hiertoe worden alle mogelijkheden onderzocht. Ook de TBS-klinieken verrichten veel inspanningen op dit terrein. Deze inspanningen dienen echter te worden aangevuld met maatregelen die een meer structureel karakter kennen, omdat in de praktijk blijkt dat slechts een klein gedeelte van de TBS-gestelden zonder legale verblijfsstatus van deze mogelijkheden gebruik kan maken.

Aan maatregelen stelt de Minister van Justitie het volgende voor: ${ }^{8}$

1. Het vorderingsbeleid van het Openbaar Ministerie wordt angepast. Indien mogelijk zal geen TBS in deze zaken worden gevorderd. Het lijkt me echter niet altijd mogelijk een vordering TBS achterwege te laten. Bijvoorbeeld als het gaat om een niet uit te zetten vreemdeling die een ernstig feit pleegde en bij wie recidivegevaar is vastgesteld. In dat geval wil ik niet het risico lopen dat de verdachte na het uitzitten van zijn straf, zonder behandeling, in Nederland op straat komt te staan.

2. Wetswijziging waardoor aan de minister van Justitie de bevoegdheid wordt toegekend de TBS tussentijds te beëindigen. Dit lijkt me aan aanwinst welke een (soms langdurige) gang naar de rechter overbodig kan maken.

3. Opzetten van aparte sobere voorzieningen. Deze sobere voorziening heeft inmiddels zijn uitwerking gekregen in de vorm van het Gritten-

8 Handelingen II, 2004-2005, 29452, nr. 13. 
veld, een afdeling binnen PI de Grittenborgh. De afdeling is formeel een onderdeel van TBS-kliniek Veldzicht te Balkbrug. Voorkomen moet worden dat vreemdelingen langdurig verblijven in een dergelijke voorziening.

\section{Ad 1. Vorderingsbeleid van het openbaar ministerie}

De aanwijzing van het openbaar ministerie 'TBS bij vreemdelingen' van 14 maart 2000, heeft als uitgangspunt dat - waar mogelijk en verantwoord tegen vreemdelingen van wie het hoogst waarschijnlijk is dat zij tengevolge van de veroordeling niet (meer) in Nederland mogen verblijven geen TBS wordt gevorderd. Deze aanwijzing wordt opnieuw vastgesteld en aangescherpt. Er zijn afspraken gemaakt tussen het openbaar ministerie en de IND aangaande de informatieverstrekking over de verblijfsstatus van een vreemdeling, zodat het OM in voorkomende gevallen geen TBS vordert als ongewenst verklaring dreigt of er sprake is van illegaliteit. Van het effect van de aanpassing vindt in 2006 een evaluatie plaats.

\section{Ad 2. Wetswijziging}

Er worden door de IND en de TBS-klinieken vele pogingen ondernomen om illegale TBS-gestelden op verantwoorde wijze over te dragen naar het land van herkomst. Indien hierover afspraken worden gemaakt en daadwerkelijk tot uitzetting over te kunnen gaan, is het echter vereist dat de TBS is beëindigd, omdat de tenuitvoerlegging van de maatregel als zodanig niet kan worden overgedragen.

Beëindiging van de TBS is momenteel alleen (tussentijds) mogelijk door intrekking van de vordering tot verlenging van de TBS (hetzij intrekking van het hoger beroep tegen een rechterlijke uitspraak tot beëindiging), door het openbaar ministerie. Teneinde in deze gevallen de mogelijkheid tot uitzetting te vereenvoudigen is er inmiddels een wetsvoorstel ingediend. Het wetsvoorstel strekt tot het verlenen van een bevoegdheid, in een nieuw artikel 38 la Wetboek van Strafrecht, aan de Minister van Justitie om met het oog op de uitzetting de TBS-maatregel te kunnen beëindigen van een illegaal in Nederland verblijvende dan wel ongewenst verklaarde vreemdeling. Aan de beëindiging zijn de volgende voorwaarden verbonden:

a. Met het land van herkomst zijn afspraken gemaakt over een passende voorziening voor de betrokken vreemdeling (voorgesteld art. 38 la, tweede lid Sr) 
b. De betrokken vreemdeling is Nederland uitgezet (voorgesteld art. 38 la, tweede lid $\mathrm{Sr}$ )

c. De betrokken vreemdeling keert niet terug naar Nederland (voorgesteld art. 38 la, derde lid Sr).

\section{Ad 3. Sobere voorziening}

Voor illegale/ongewenste vreemdelingen met TBS wordt een sobere voorziening gecreëerd, die primair gericht zal zijn op uitzetting van de desbetreffende vreemdelingen en vanuit dat perspectief bezien adequate verzorging biedt. In de voorziening wordt dus de benodigde psychiatrisch/medische zorg geboden, mede met het oog op de beoogde uitzetting van betrokkene. Er vindt geen behandeling gericht op resocialisatie in de Nederlandse samenleving plaats. Zo kan het reguliere verloftraject geen deel uitmaken van de behandeling. Door het creëren van een specifieke voorziening kan ook expertise worden gebundeld ten aanzien van de uitzetting van de doelgroep. In de gevallen dat uitzetting (nog) niet mogelijk is, kan een langduriger verblijf binnen de TBS - vergelijkbaar met een long-stayvoorziening - noodzakelijk zijn. ${ }^{9}$

\section{Slot}

Nadat de Commissie Visser haar werkzaamheden afrondde zijn kort daarop enkele concrete verbetervoorstellen tot stand gekomen. Dit zijn bijna allemaal voorstellen die in het verlengde liggen van wat de Commissie voor ogen had. De zin van het parlementaire onderzoek staat daarmee naar mijn mening vast.

9 Handelingen II, 2003-2004, 29537, nr. 9. 